\title{
Status and trends in the global growth of Koedoe between 1958 and 2016
}

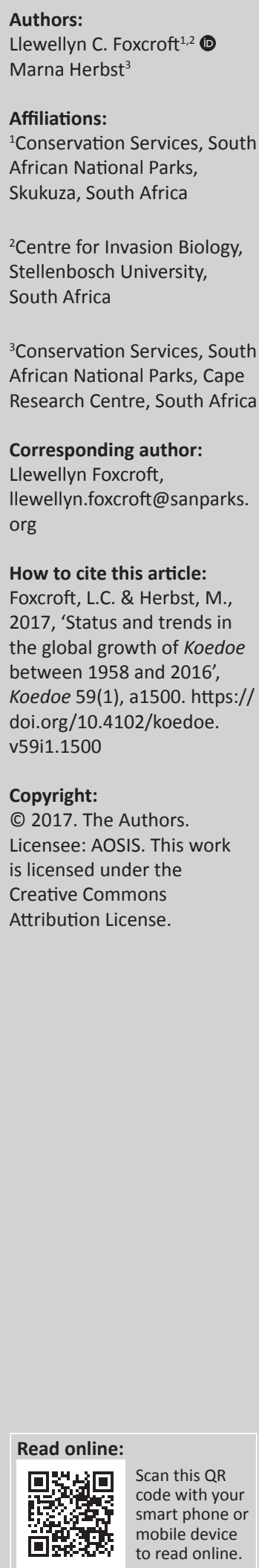

The process of scientific publishing is highly competitive and the prestige associated with journals is a key consideration of where authors choose to publish their research. Journals need to provide relevant, high-quality publications that add to the body of literature to provide updated information upon which evidence-based management can be implemented. In addition, scientists want their work to be accessible and with the evolution of web-based publishing, articles that were difficult to access in the past can now be made immediately available worldwide. To remain relevant and expand globally beyond its previous reach, Koedoe launched its online platform in 2008. Since then it has shown strong annual growth rates, which is illustrated by the number of articles being downloaded more than 265000 times in 2016 alone. In addition, by 2016, the total number of all Koedoe articles downloaded exceeded 1.3 million.

The launch of Koedoe in 1958 was aimed at providing a platform to capture important baseline information and research specifically on protected areas and national parks in South Africa. The focus has expanded to include science across the African continent, addressing important management questions both in the biophysical sciences and more recently socio-ecological and economic studies. To date, about 1250 articles have been published in Koedoe. Publishing Koedoe as a fully open access online journal also brought with it additional opportunities. For example, all articles from the first issue of Koedoe in 1958 were scanned and included in the Koedoe website, making over 50 years' worth of scientific knowledge easily available. The importance of making past research available can be illustrated by the example of the focus around savanna fire ecology, a key research theme in the Kruger National Park. The third article published in Koedoe was a report on fire research in the Kruger National Park (Inleidende verslag oor veldbrandnavorsing in die Nasionale Krugerwildtuin; Van der Schijff 1958). This information would not have been easily accessible and knowledge may have been lost; however, since 2008 this article has been viewed about 4456 times on the website. The increasing visibility and use of articles positioned Koedoe to be able to apply for accreditation with international bodies that use various metrics to benchmark journals. One of the frequently used benchmarks is Clavariate Analytics Journal Citation Reports (formerly Thomson-Reuters Web of Science). Koedoe received its first impact factor in 2013 with 1.48, and has since fluctuated between 1.48 and 0.52 .

This article provides (1) a brief overview and literature analysis of articles published in Koedoe since 1958 and (2) an update on the status and trends of readers interacting with the Koedoe website and articles being downloaded. Most of the results are only for data up to 2016 to include a complete year; however, in some cases, information from 2017 is also given.

\section{Overview and literature analysis}

A bibliometric analysis of keywords that have featured in Koedoe articles since 1958, summarised by decades, provides some insights into the themes that were researched over time. Keywords were taken from the titles of all articles and grouped a priori to show patterns of priorities. Trends indicate that articles have consistently shown an increase in the number of downloads, even when accounting for the number of articles published in that decade (Figure 1). For example, except for 1958-1969, the highest number of downloads was for articles published between 2000 and 2009; however, the lowest number of articles were published during this period. Although the period from 2010 to 2019 is not complete and only 142 articles have been published to date, the number of downloads is already higher than pre-2000 publications. This also illustrates that while Koedoe has maintained a constant level of interest, it suggests an increase in readership and the value of articles.

Encouragingly, articles published before 2000 are still consistently downloaded, showing the importance of accessibility to the information that has been published in Koedoe in the past (Figure 2). 
The number of articles published per year has fluctuated, often when special issues are published. However, since the late 1980s, there have been, on average, more than 20 articles a year.

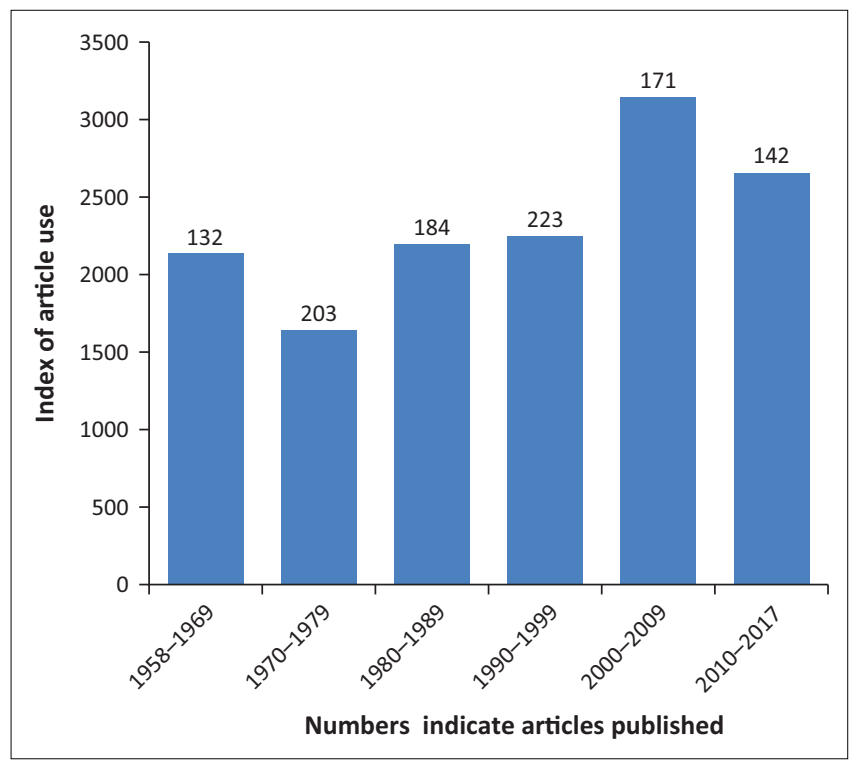

FIGURE 1: The number of downloads divided by the number of articles published per decade. Values above the columns indicate the numbers of articles published per decade.
An analysis of trends in keywords extracted from the titles of articles published in Koedoe provides an indication of some of the priorities over time (Figure 3). Publication of inventories has remained important throughout the history of Koedoe, with species lists being continuously updated as poorly surveyed areas or taxa receive attention. Waterrelated themes became a major focus area in the 1990s, linked in part to the Kruger National Park Rivers Research

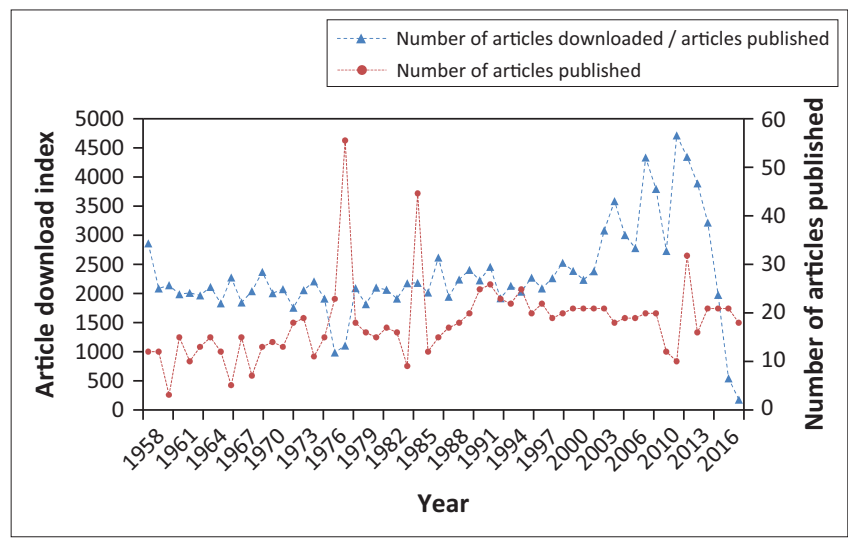

FIGURE 2: The number of downloads divided by the number of articles published per year. The number of articles downloaded/articles published from about 2013 onwards have not had enough time to give an accurate reflection.

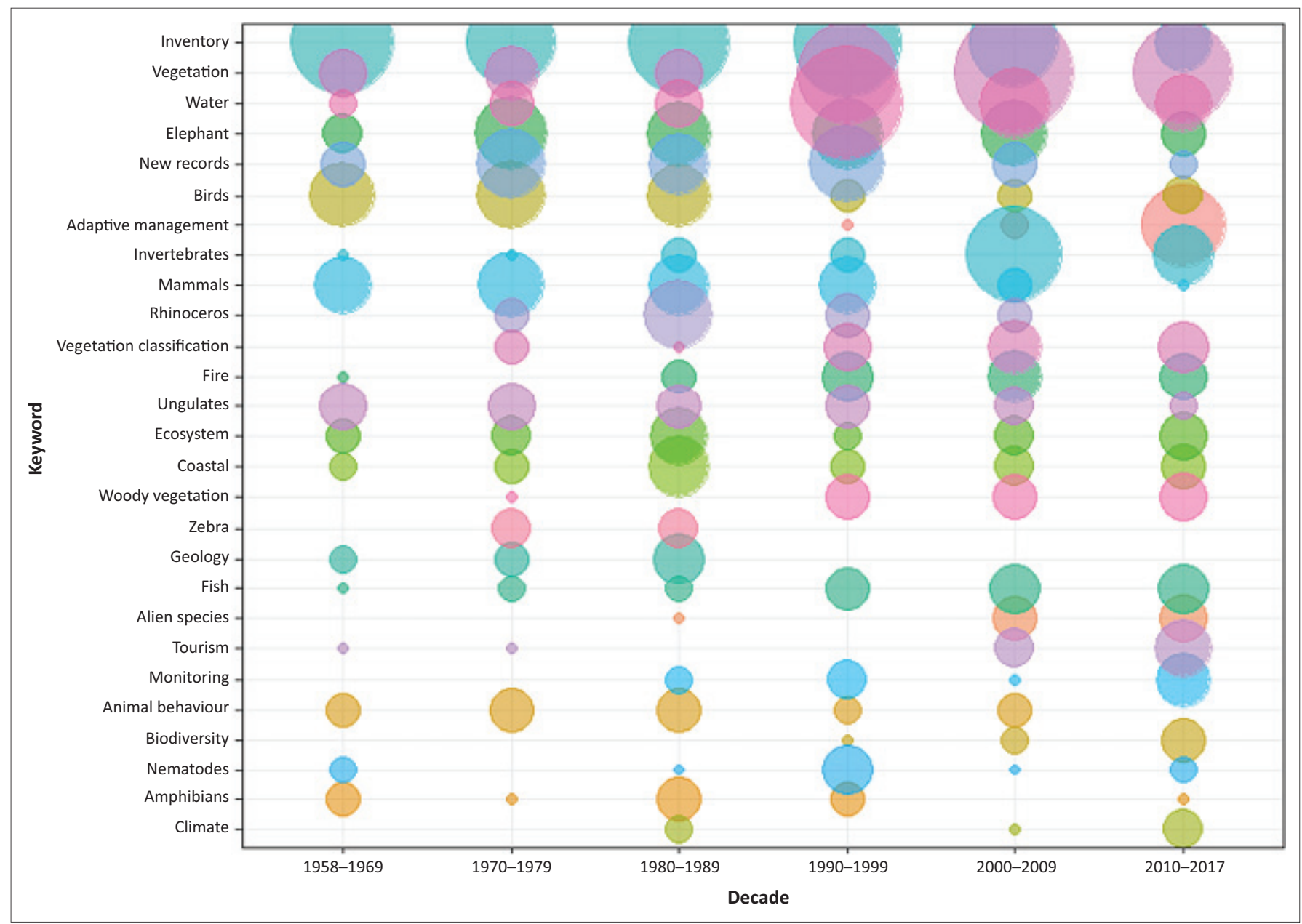

Source: Sandra MacFadyen

FIGURE 3: Bubble plot showing the most frequently listed words in article titles, analysed per decade. The size of the circle indicates the frequency of keywords as an indication of active fields of research. 
Programme (KNPRRP; McLoughlin et al. 2011) and the ongoing concern around river health. This can be seen with the increasing amount of work around fish monitoring. Adaptive management only emerged between 1990 and 2009, partly as an outcome of the KNPRRP, but expanded to become a major focus area since 2010 (Roux \& Foxcroft 2011). As part of the development of knowledge on wildlife management, animal behavioural studies remained important themes until 2000-2009 era. This evolved more broadly into biodiversity studies from about 2000 and has continued growing as an area of interest.

Analysing the origin of the research published provides indirect insight into two aspects: (1) for SANParks especially, priority research sites over time and (2) in general, the distribution of scientists across Africa who have published in Koedoe. Articles have originated overwhelmingly from the Kruger National Park, and until the end of the 1990s also in the Kalahari Gemsbok National Park, although with a declining focus from the latter in recent years (Figure 4). In the first 10 years of Koedoe, articles largely originated from nine protected areas or national parks. Since the start of Koedoe, articles have originated from at least 58 different areas, and from 2010 from 30 different protected areas.

\section{Status and trends in Koedoe's global reach: 1958-2016}

Koedoe continued to show substantial growth in 2016, with the number of articles downloaded from the entire collection (1958-2016) exceeding the 1.3 million milestone, having been downloaded a total of 1311840 times (only PDF and HTML, but excluding ePUB and XML versions, which totals 3046 417 downloads). This showed a $27.8 \%$ increase from the 2015 cumulative total of 945950 times. The 2015 total was already a 30.1\% increase from 660472 in 2014. There was an increase in the number of papers downloaded annually, from 285475 downloads in 2015 to 365890 downloads in 2016 (Figure 5).

While the number of website visitors has decreased slightly, there were still more than 130000 unique site visitors and 225000 visitors, leading to about 800000 page views. This indicates that while there are fewer site visits, more articles are being downloaded by these visitors. Data from Crossref (http://www.crossref.org) showed that Koedoe received a total of 268 unique citations (articles cited for the first time) in 2016. Although the number of citations accumulates with time, the 268 citations in 2016 have already surpassed the 200 citations in 2015. The citations to articles published in 2014 continued to grow steadily to 602 . The article that received

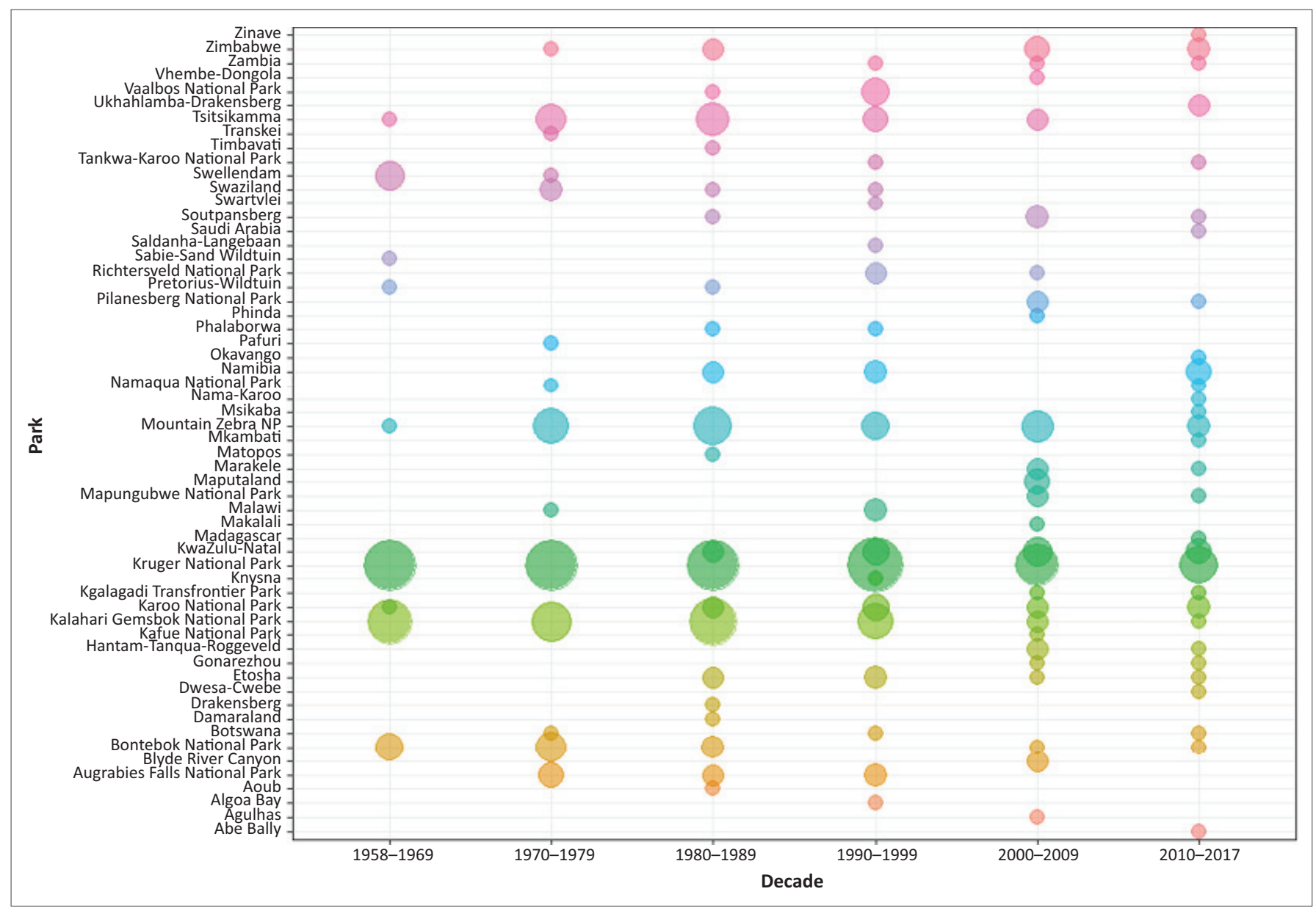

Source: Sandra MacFadyen

FIGURE 4: Bubble plot showing the most frequently listed National Parks or other research sites in article titles, analysed per decade. The size of the circle indicates the frequency of the protected area name as an indirect indication of key focus areas over time. 
the most citations (100) in 2016 is 'Landscapes of the Kruger National Park' (Gertenbach 1983).

Data from Google Analytics provide insights into the distribution of countries from which site visits originate. The top 10 countries from which visits to the Koedoe website originated accounted for 42551 of the visits, with South Africa representing approximately half of these. As Koedoe aims to make science available across the continent, it is encouraging to see that nine African countries have all had more than 100 site visits. These include Kenya, also being the fourth highest overall (1626), Botswana (746) and Zimbabwe (462) (Figure 6). The number of visits to the website from the United States, United Kingdom, Australia, India and Germany illustrates the widespread reach of Koedoe.

Between 2008 and 2016, 173 articles were published, including a special issue on adaptive management in 2011 (19 articles) and a special issue on tourism in 2014 (10 articles). Both of the special issues have received much interest, with the special issue on adaptive management (http://www.koedoe.co.za/index.php/koedoe/issue/ view/82) being downloaded a total of about 212700 times (as at September 2017). The more recent special issue on tourism (http://www.koedoe.co.za/index.php/koedoe/ issue/view / 86) has been downloaded about 63800 times (as at September 2017). A third special issue, titled 'Natural resources research: Implication for management and conservation', was published during 2017.
Koedoe will soon be celebrating its 60th anniversary in the publication of protected area management and conservation science. Many milestones have been reached, with numbers of downloads increasing annually, the publication of two highly successful special editions and the Journal Citation Report impact factor. Koedoe is growing in the publication of manuscripts that address pressing challenges to conservation across the continent, including adaptive management, water, tourism, climate change and social-ecological systems. Koedoe is providing a niche for relevant publications that are widely accessed and highly visible in the management of protected areas and conservation science.

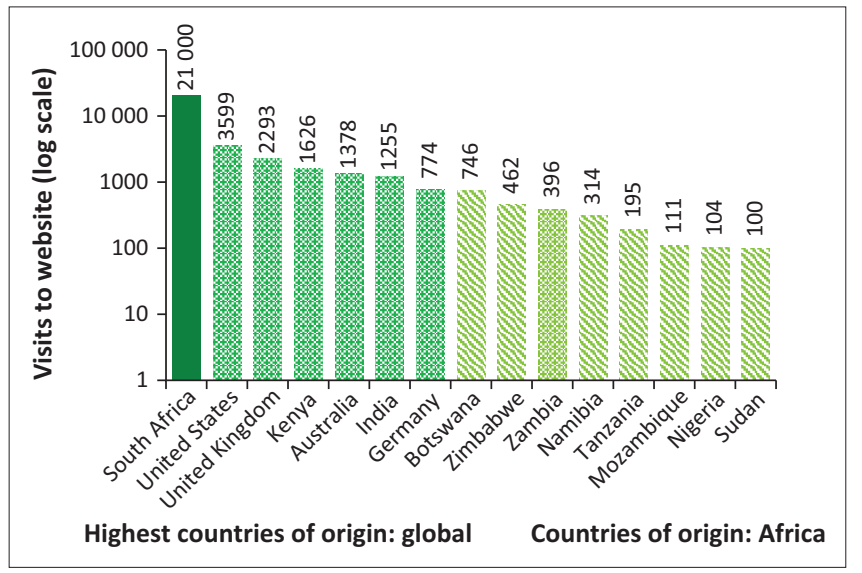

FIGURE 6: The number of visitors to the Koedoe website per country (Google Analytics). The darker shade of green shows the highest number of visitors by origin, with the lighter shade indicating the number of site visits from African countries.

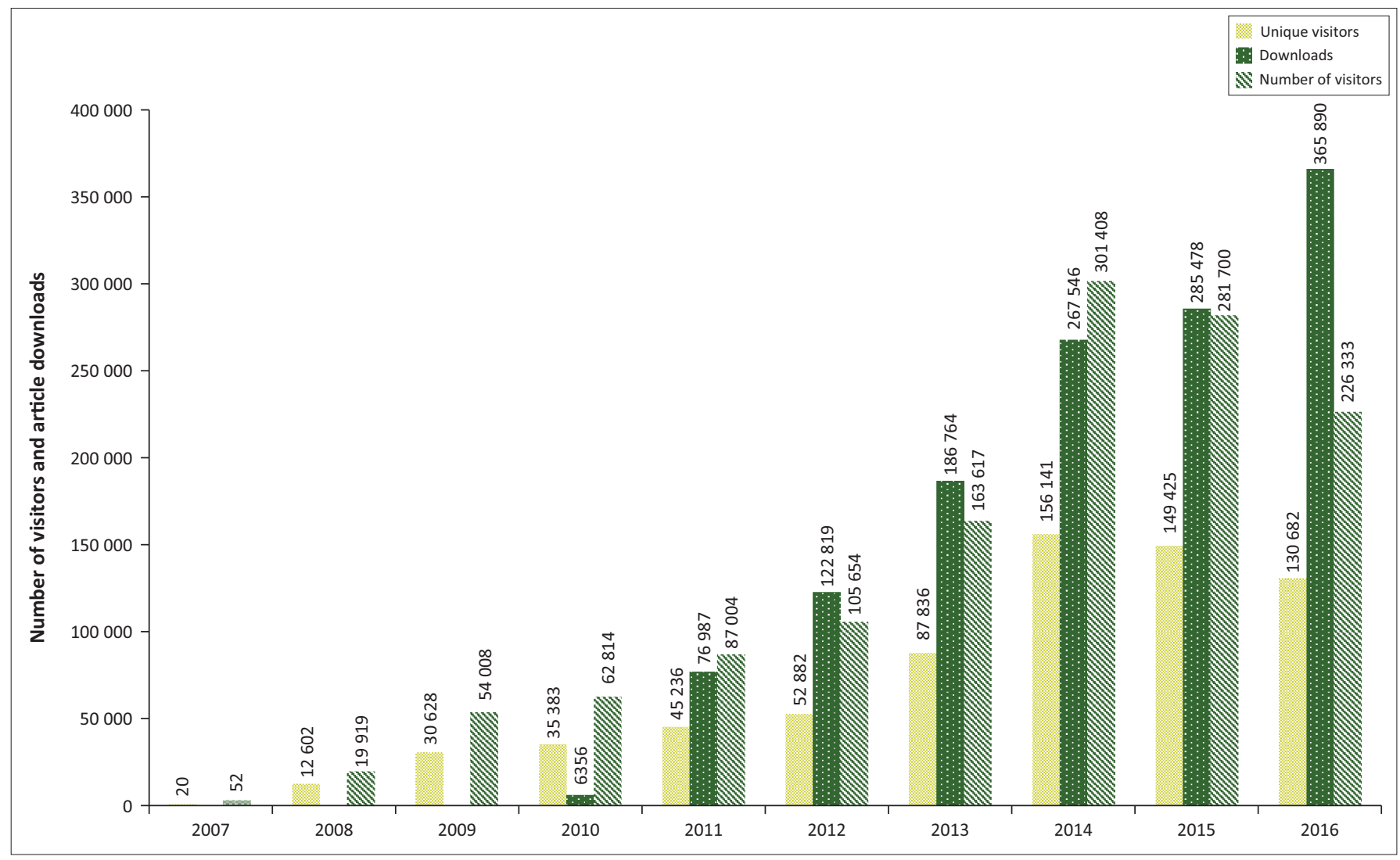

FIGURE 5: The number of article downloads and visitors to the Koedoe website. Download data in 2010 were only available for part of the year and not recorded between 2007 and 2009. 


\section{Acknowledgements}

We thank South African National Parks for ongoing support for Koedoe. We thank all editors and reviewers for their valuable time and expertise given to Koedoe. We acknowledge the AOSIS editorial team for their support. Sandra MacFadyen conducted the analysis and provided Figures 3 and 4 .

\section{Competing interests}

The authors declare that they have no financial or personal relationships that may have inappropriately influenced them in writing this editorial.

\section{Authors' contributions}

L.C.F. and M.H. developed the concept. L.C.F. led the writing and M.H. gave input on the manuscript.

\section{References}

Gertenbach, W.P.D., 1983, 'Landscapes of the Kruger National Park', Koedoe 26(1), 9-121. https://doi.org/10.4102/koedoe.v26i1.591

McLoughlin, C.A., Deacon, A., Sithole, H. \& GyeduAbabio, T., 2011, 'History, rationale, and lessons learned: Thresholds of potential concern in Kruger National Park rive adaptive management', Koedoe 53(2), Art. \#996, 1-27. https://doi.org/10.4102/ koedoe.v53i2.996

Roux, D.J. \& Foxcroft, L.C., 2011, 'The development and application of strategic adaptive management within South African National Parks', Koedoe 53(2), Art. \#1049, 1-5. https://doi.org/10.4102/Koedoe.v53i2.1049

Van der Schijff, H.P., 1958, 'Inleidende verslag oor veldbrandnavorsing in die Nasionale Krugerwildtuin', Koedoe 1(1), 60-94. https://doi.org/10.4102/koedoe.v1i1.865 